\title{
Suicídio de universitários: o vazio existencial de jovens na contemporaneidade
}

\section{University student's suicide: existential emptiness in contemporary times}

\section{Elza Dutra*}

Universidade Federal do Rio Grande do Norte - UFRN, Natal, Rio Grande do Norte, Brasil

\begin{abstract}
RESUMO
Estudos realizados na região nordeste com estudantes universitários dos cursos de medicina e de psicologia evidenciam um alto índice de ideação e de tentativas de suicídio entre eles. Ao mesmo tempo, não são incomuns as notícias de suicídio de estudantes em instituições de ensino superior, em universidades da região nordeste e sudeste, como por exemplo, Pernambuco e Rio de Janeiro. Partindo dessas evidências, este trabalho desenvolve reflexões acerca do contexto acadêmico, social e existencial em que tal fenômeno ocorre. Para isso recorre-se a algumas ideias da Analítica Existencial, tais como angústia, tédio e técnica. Espera-se que as discussões empreendidas possam acrescentar ao campo de estudo, bem como despertar as instituições acadêmicas para a importância desse fenômeno e, assim, favorecer a criação de estratégias de cuidado e solicitude que possam acolher o aluno em sua dimensão existencial.
\end{abstract}

Palavras-chave: suicídio de universitários, suicídio e analítica existencial, tédio e suicídio, fenomenologia heideggeriana.

\begin{abstract}
Studies conducted in Brazilian Northeast region with medicine and psychology university students show a high rate of suicidal ideation and suicide attempts among them. At the same time reports of suicidal attempts in higher education institutions in northeast and southeast region such as Pernambuco and Rio de Janeiro are not uncommon. Based on these data, this work relies on some existential analysis ideas such as anguish, boredom and technique to understand the academic, social and existential contexts where the phenomenon occurs. It is hoped that the discussion on the subject calls attention to the relevance of the problem and foster the development of strategies for care and acceptance of the student's existential dimension.
\end{abstract}

Keywords: student's suicide, suicide and existential analysis, suicide and boredom, Heideggerian phenomenology. 


\section{Introdução}

Não são raras as notícias sobre suicídios de estudantes universitários no Brasil. Independente da região do país onde o ato ocorra, é significativa a estatística de suicídio desses jovens, embora o registro de tais ocorrências não corresponda à realidade. Sabe-se mais pelas notícias veiculadas na mídia e internet (redes sociais e blogs) do que por registros oficiais. Vale ressaltar que o mesmo ocorre em relação ao suicídio como um todo. Ou seja, os preconceitos e significados que permeiam esse fenômeno, como por exemplo, valores religiosos e morais, muitas vezes impedem que um ato dessa natureza seja identificado como tal. Não é raro que esse acontecimento seja interpretado como um acidente ou morte natural. E quando o suicídio é interrompido, no caso da tentativa de suicídio (TS), o sub-registro acontece com mais facilidade e frequência, uma vez que a TS, na maioria das vezes, ocorre por meio de ingestão de medicamentos e pesticidas (DUTRA, 2007; MS-SIM, 2006, MELEIRO, 1998; MIRANDA E QUEIROZ, 1991, o que favorece a distorção na interpretação ou na negação do ato.

Tendo como referência alguns estudos realizados sobre essa temática, nos propomos, neste trabalho, a iniciar uma discussão acerca do suicídio de universitários numa perspectiva fenomenológico-hermenêutica heideggeriana, interrogando sobre os sentidos existenciais desse ato, considerando-se a condição de serno-mundo de seus autores.

Com o intuito de fornecer uma visão estatística desse fenômeno, recorreremos a dados oficiais sobre a ocorrência do suicídio no mundo e no Brasil. Posteriormente nos debruçaremos sobre o fenômeno do suicídio sob uma ótica distinta daquelas por meio das quais o suicídio comumente é interpretado.

\section{Contexto epidemiológico do suicídio}

Em termos epidemiológicos, a cada ano, em todo o mundo, o suicídio atinge 0 índice de 16 mortes para cada 100.000 habitantes, representando uma morte a cada 40 segundos. Cerca de um milhão de pessoas cometem o suicídio, segundo a Organização Mundial de Saúde (OMS-2001), enquanto que entre 10 e 20 milhões tentam matar-se. De acordo com a OMS, o suicídio encontra-se entre as dez principais causas de morte em todo o mundo, para todas as faixas etárias, incluindo jovens e adultos jovens com idade entre 15 e 35 anos (OMS, 2000), entre as três principais. Nos últimos 45 anos, os índices de suicídio aumentaram $60 \%$ em todo o mundo. Estudos epidemiológicos atuais têm revelado um aumento na prevalência de suicídios, com dados estatísticos bastante preocupantes. 
No Brasil, o mesmo acontece. O número de suicídios vem aumentando significativamente, principalmente entre jovens e adultos jovens. No ano de 2000, segundo o Ministério da Saúde (SIM, 2006), o total de suicídios no país foi de 6.780 ocorrências, em todos os sexos e faixas etárias, representando uma taxa de 3,99 óbitos para cada 100.000 habitantes. Já no ano de 2007, a TME (Taxa de Mortalidade Específica) representou 5,8 para cada 100.000 habitantes, revelando um aumento bastante significativo em comparação ao ano de 2000.

No que se refere aos jovens na faixa etária dos 20 aos 24 anos, no Brasil, em 2007, o suicídio dessa população alcançou a taxa de 5,4 para cada 100.000 habitantes, o que representa um índice extremamente preocupante. Pois é justamente nessa faixa etária que esses jovens estarão adentrando no mercado de trabalho, nos cursos técnicos ou de nível superior, enfim, encontram-se efetuando escolhas e definindo os seus destinos na vida, construindo e realizando os seus projetos de vida. Assim, tendo em vista esse número de mortes por suicídio, uma pergunta clama por um entendimento: o que faz com que esses jovens não estejam desejando viver? Que contexto de mundo é esse que favorece o aumento do número de jovens que preferem não viver?

Os estudos sobre adolescentes e adultos jovens que tentam suicídio têm sido bastantes presentes na literatura mundial e no contexto do nosso país. Por exemplo, um estudo sobre suicídio de adolescentes no Brasil revelou que Porto Alegre e Curitiba apresentam as maiores taxas de suicídio em adolescentes, entre nove capitais brasileiras (SOUZA, MINAYO \& MALAQUIAS, 2002). Considera-se que na adolescência os indivíduos podem recorrer a comportamentos ditos agressivos, impulsivos ou suicidas para solucionar os seus problemas. Em relação ao gênero, foi demonstrado que durante essa fase as mulheres apresentam maiores taxas de ideação suicida do que os homens. A explicação apresentada é que já na adolescência as meninas apresentam maiores índices de depressão e de desesperança do que os meninos (BORGES \& WERLANG, 2006).

No que se refere, especificamente, a ideação e tentativas de suicídio de estudantes universitários, a produção científica no Brasil ainda se mostra bastante incipiente, considerando-se a significativa estatística de suicídio de jovens, como mencionado antes. A literatura mostra que uma das populações mais abordadas em pesquisas sobre ideação e TS tem sido a de estudantes de medicina. Em relação a essa população, é possível apontar alguns estudos significativos, embora a maior parte deles tenha sido desenvolvida nas regiões Sul e Sudeste (MELEIRO, 1998; MIRANDA E QUEIROZ, 1991; CORDÁS et al, 1988). Na região Nordeste, um dos estudos pioneiros sobre esta população (DUTRA, 2005), revela uma significativa relação entre alguns fatores de risco como a depressão, abuso de álcool e desejo de morrer e 
tentativa de suicídio entre esses estudantes. No estudo mencionado foram investigados 152 alunos da maior universidade pública do estado; os resultados mostraram que um aluno $(0,7 \%)$ havia cometido uma tentativa de suicídio.

Entretanto, esta pesquisa verificou outros achados, como o uso e abuso de álcool pela maioria dos estudantes, inclusive as mulheres; um número significativo (25\%) de alunos que pensavam em se matar, além da presença de estados depressivos entre eles. Quanto ao baixo número de tentativas de suicídio, somente uma, o que contraria resultados de estudos desenvolvidos com essa população na região sudeste (MIRANDA E QUEIROZ, 1991; MELEIRO, 1998), Dutra (2005, p. 297) sugere que "tal resultado não afasta a preocupação em relação à saúde mental desses jovens; "primeiro, pelo fato de o "suicídio" ser um tema polêmico, ainda tabu, o que pode fazer com que o pesquisado não responda de forma sincera à pergunta feita".

Pesquisas estatísticas foram realizadas por Dutra $(2007 ; 2008) \mathrm{com}$ 637 estudantes de psicologia, em duas universidades (uma pública e uma privada) e duas faculdades, na cidade de Natal-RN. E em João Pessoa-PB, foram pesquisados 374 estudantes do curso de psicologia da maior universidade pública do estado. Os resultados são preocupantes, pois entre os 637 alunos que responderam ao questionário de pesquisa, no $\mathrm{RN}, 52,45 \%$ disseram que sentiam vontade de morrer; 48 dos estudantes pesquisados, representando $7,5 \%$ do total, haviam tentado se matar. No estudo realizado na Paraíba, os dados são ainda mais preocupantes, se comparados aos achados no RN. Entre os 374 alunos que responderam ao questionário aplicado, 43 pessoas haviam tentado se matar, representando $11,49 \%$ da população pesquisada. Tais resultados já seriam suficientes para justificar a realização de outros estudos visando ao maior conhecimento e reflexão sobre os fatores e aspectos psicossociais e existenciais favorecedores desse ato.

Estudos sobre estresse, identificado como um aspecto relacionado ao suicídio, têm sido frequentes na literatura científica, inclusive no Brasil. Calais, Andrade e Lipp (2003) investigaram o estresse em adultos jovens, relacionando-o à escolaridade e ao sexo. $O$ estresse, para as autoras, é definido como "uma reação intensa do organismo frente a qualquer evento bom ou mau que altere a vida do indivíduo. Essa reação ocorre, em geral, frente à necessidade de adaptação exigida do indivíduo em momentos de mudança" (p. 257). O estudo mostrou que os estudantes de pré-vestibular são os que mais sofrem de estresse, seguidos do terceiro ano do ensino médio e dos alunos do primeiro ano do nível superior. Por sua vez, Sarriera, Berlim, Verdin e Câmara (2004), num estudo sobre jovens desempregados, observaram que, diferentemente dos demais jovens, estes apresentavam sentimentos de auto-desvalorização e riscos de 
depressão e apatia, os quais poderiam levá-los a comportamentos anti-sociais e desprezo pela vida.

Até o momento atual, como mencionado, não foi localizado, nas fontes de pesquisa bibliográfica, produção científica significativa sobre o suicídio e TS de estudantes universitários no Brasil. Entretanto, não são raras as notícias veiculadas na mídia sobre ocorrências em algumas universidades, como, por exemplo, na UFPE, na região Nordeste, e na UERJ, no Sudeste.

O aumento nas taxas de suicídio entre jovens não ocorre somente no Brasil, mas também e, principalmente, em países de primeiro mundo. Os Estados Unidos, por exemplo, país detentor de taxas expressivas de suicídio e de tentativas de suicídio, tem produzido relevantes estudos sobre essa temática. De acordo com pesquisas desenvolvidas pelo Suicide Prevention Resource Center-SPRC (2004), entre estudantes universitários com idade entre 20 e 24 anos, o suicídio é a terceira causa de morte, estando o homicídio como a segunda causa. Os serviços de aconselhamento dos campi universitários têm detectado um aumento na procura deste serviço pelos estudantes. Os dados coletados mostram uma prevalência de depressão e de ideação suicida entre os estudantes.

Por sua vez, nesse mesmo país, um consórcio de 36 centros de aconselhamento detectou, entre estudantes de várias universidades, aumento de ansiedade, medo, distúrbios de alimentação, abuso de álcool e outras drogas, raiva e hostilidade entre colegas. O mesmo estudo encontrou significativo aumento no impacto da violência, na dinâmica familiar, aumento da depressão e desordens bi-polares.

Estudos demográficos foram desenvolvidos por (SILVERMAN; MEYER; SLOANE; RAFFEL; \& PRATT, 1997) sobre os suicídios nos campi universitários americanos, com estudantes de graduação e pósgraduação, no período entre 1980 e 1990. O maior número de suicídios ocorreu entre estudantes de 20 a 24 anos (46\%), entre alunos de graduação (32\%).

Um estudo de 13 anos foi realizado por pesquisadores da Kansas University (1989-2001), entre 13 mil estudantes que haviam procurado 0 serviço de aconselhamento. Os pesquisadores observaram que os estudantes sofriam de mais estresse, mais ansiedade e mais depressão, do que uma década atrás. O aumento, segundo os pesquisadores, foi dramático, uma vez que a estatística do número de suicídios triplicou.

Outros pesquisadores verificaram que o estresse entre os estudantes se relacionava com a performance acadêmica. Corroborando esta ideia, os estudos de Kitzrow (2003) mostraram que "problemas de saúde mental têm um impacto negativo na performance acadêmica, na permanência e nas taxas de conclusão" (p.171).

0 abuso de substâncias, em particular, o álcool, também atinge a saúde do estudante e o seu desempenho acadêmico, relacionando-se 
com as tentativas de suicídio. (WATERS \& DUTRA, 2006). Wechsler; Lee; Kuo \& Lee, (2000) relatam que $44 \%$ dos estudantes se definem como "grandes bebedores". O National Institute on Alcohol Abuse and Alcoholism (2002) relata que em torno de 1.400 estudantes morrem cada ano de doenças relacionadas ao abuso de álcool.

Para o SPRC (2004), o suicídio tem sido descrito como o final de um continuum que começa com a ideação, segue com o planejamento e a preparação do suicídio e termina com a tentativa e o suicídio completo (KACHUR, POLTER, POWEL \& ROSENBERG, 1995).

Um estudo de (BARRIOS, EVERETT, SIMON \& BRENER, 2000) mostrou que há uma relação entre suicídio, depressão e abuso de álcool e outras drogas. Os autores verificaram que aqueles estudantes que relataram ideação suicida eram mais propícios a portarem armas, se envolver em brigas, nadar embriagados, dirigir embriagados e raramente usavam cinto de segurança. Todos esses estudos, em parte ou na totalidade, se assemelham aos resultados encontrados nas pesquisas realizadas no Brasil, em relação aos fatores de risco. Constata-se que a depressão, o uso de drogas, entre elas o álcool, famílias desagregadas, etc., têm uma relação próxima com as condutas autodestrutivas de estudantes universitários.

\section{Fatores de risco do suicídio e das tentativas de suicídio}

Alguns fatores de risco do suicídio e das tentativas de suicídio têm sido identificados nos estudos realizados tanto em outros países como no Brasil. Fatores como transição de vida, ou seja, deixar a casa dos pais para frequentar a universidade - pode exacerbar as dificuldades psicológicas. Deixar a família e entrar num ambiente não familiar com altos padrões acadêmicos pode causar depressão ou altos níveis de angústia.

O estresse é um fator significativo em qualquer modo de se entender o comportamento suicida. Estima-se que uma perda interpessoal, um grande conflito com um parente, ou namorado(a), está presente em $70 \%$ dos casos de tentativas de suicídio e de suicídio. Essa compreensão, aliada a um senso de responsabilidade, tornam 0 adolescente e o adulto jovem mais suscetível ao estresse associado à escola, estudos ou problemas sociais. Nessa fase de desenvolvimento, eles podem antecipar o impacto do seu comportamento todo o tempo, o que faz com que as questões possam ser percebidas como uma possível causa de estresse e problemas futuros e assim precipitar atos autodestrutivos na população adolescente.

Além dos já apresentados, devemos considerar outros fatores que podem favorecer o suicídio, como por exemplo: o uso abusivo de álcool e drogas; a disponibilidade dos meios para efetuar o ato 
suicida; a violência física na infância; a violência sexual na infância; o isolamento social; os distúrbios psíquicos como a depressão, a esquizofrenia ou sentimentos de desesperança, além de, por fim, um histórico de tentativa de suicídio, o que é considerado na literatura como a mais forte variável (WERNECK et al., 2006).

No entanto, além dos estudos citados aqui, quase sempre apontando para causas psicossociais, para os transtornos psiquiátricos e desajustes emocionais, é oportuno refletirmos sobre a dimensão existencial desse fenômeno, sem que se eliminem os aspectos apresentados, entendendo-os como motivos, e não, causas. Pensar o contexto de mundo e ser-no-mundo do Dasein e como o suicídio poderia ser interpretado à luz de um pensamento que compreende o homem na sua condição de indeterminação e poder-ser.

\section{Da angústia e do tédio do ser-no-mundo-com-outros}

Diversas são as interpretações do suicídio. Partindo de diferentes campos de saber, como a Antropologia, Psicologia, Psiquiatria e Filosofia, só para citar alguns, são muitas e distintas, e quase sempre divergentes, as visões sobre esse ato. Mas arriscamos dizer, no que tange ao suicídio que, sob o olhar da ciência, prevalece uma visão objetivista, por meio da qual se busca encontrar causas explicativas para o fato de alguém não mais desejar viver.

Entretanto, é possível abordar o suicídio de várias outras maneiras. Uma delas é considerar o ser humano como um Dasein, tal como o faz Martin Heidegger em sua Ontologia Fundamental. Dasein, ser-aí, ser-no-mundo, dizem da indeterminação de um ente que pensa, existe e se desvela como possibilidade de Ser no mundo que se abre diante dele enquanto pré-sença. No prefácio de Introdução à Metafísica (HEIDEGGER, 1999), Emmanuel Carneiro Leão afirma:

O homem não pode existir senão em comércio e comunhão com o mundo dos entes. Ente significa tudo que de algum modo é: o homem, as coisas, os acontecimentos, até mesmo o Nada, enquanto é um Nada, i.é, enquanto tem um significado, seja positivo ou negativo para a existência. Incluindo o seu modo de ser, tudo que é, é um ente, e tudo que implica ou se refere ao ente e seu modo de ser, é ôntico, adjetivo formado da palavra grega, on (=ente).

No entanto, continua ele:

O Ser nunca é diretamente acessível. Como diferença ontológica, inclui sempre uma irredutibilidade ao ente. Nunca poderá ser objetivado. Nunca poderá ser encontrado nem como ente, nem dentro do ente. Nunca poderá ser constatado a modo de um dado, fato ou valor objetivo. O Ser 
só se dá obliquamente, enquanto, retraindo-se e escondendo-se em si mesmo, ilumina o ente segundo determinada figura de sua Verdade (p. 16).

Assim, ainda que nos encontremos em uma cultura, ocidental, na qual prevalece uma forma de pensamento fundamentado por uma ontologia que interroga sobre o que é o ser e não sobre o sentido do ser, como o faz Heidegger (1927/1999), e desse modo buscando verdades universais e absolutas, é possível se desconstruir, ou tentar, refletir sobre um fenômeno como o suicídio, de uma maneira que contemple a dimensão indeterminada e de poder-ser a que 0 pensamento fenomenológico-hermenêutico heideggeriano nos conduz.

Temos pensado no suicídio como um modo de se lidar com a angústia, que é constitutiva do Dasein, eliminando-a. Como a angústia permite ao Dasein colocar-se diante da possibilidade de sersi-próprio, isto é, de singularização, ele escolhe a finitude, o serpara-a-morte. No entanto, temos acrescentado às nossas reflexões um pensar que leve em conta a questão do tédio e as implicações dessa tonalidade afetiva na existência, em um mundo pós-moderno, hipervirtualizado ou contemporâneo, seja como for chamado o mundo atual. Mas o que distinguiria essas duas tonalidades afetivas, uma vez que angústia e tédio se aproximam em seu caráter de abertura ao ser-si-próprio?

Feijoo (2010) reconhece essa questão ao dizer que Tédio e angústia constituem-se em tonalidades afetivas fundamentais que viabilizam a crise do projeto do impessoal, abrindo espaço para que a singularização se dê. Na angústia, há um repetido esvaziamento do sentido que sustenta o movimento existencial cotidiano, e tudo, então, se mostra como possibilidade. No tédio, todo o campo temporal desaparece, o ser-aí não temporaliza mais, e o nada se mostra na total ausência de possíveis (p. 158).

Ou seja, a angústia surge na obra Ser e Tempo (1927/1999) como constitutiva do Dasein, enquanto que em Os Conceitos Fundamentais da Metafísica (2006), o tédio profundo ocupa as reflexões filosóficas de Heidegger como uma tonalidade afetiva característica da cultura do mundo da técnica. Portanto, além de oportuna, numa época em que a técnica é reificada, a noção de tédio nos permite pensar acerca do sofrimento do homem contemporâneo e a perda do seu poder-ser diante da condição de ausência da historicidade e de tempo da sua existência.

A tonalidade afetiva, tradução do termo Befindlichkeit, assim como disposição afetiva, humor, sentimento e afetação, (FORGUIERI, 1993; GENDLIN, 1978/1979; NOVAES, 2010; DUTRA, 2008), indica a condição afetiva que constitui as experiências de ser-no-mundo-com- 
outro. Referindo-se à tonalidade afetiva, Heidegger diz que "Tonalidades afetivas são jeitos fundamentais nos quais nos encontramos de um modo ou de outro. Tonalidades afetivas são o como de acordo com o qual as coisas são para alguém de um modo ou de outro" (2006, p. 81).

No tédio, a tonalidade afetiva que, segundo o filósofo, se apresenta em três modos, o que se sobressai é a temporalidade, tal como é extensa e profundamente discutido por Heidegger (2006). Ao mesmo tempo, a temporalidade evoca a historicidade, tornando-se, ambas as dimensões, perdidas, quando se vive o tédio profundo, proposto por ele como o terceiro modo do tédio.

Ao tematizar o tédio, Feijoo esclarece que

\begin{abstract}
No tédio, o ser-aí se depara com uma recusa de todas as coisas, como fechamento de possibilidades de realização do mundo. O tédio traz à tona o mundo como espaço de singularização do ser-aí, bem como espaço de diferenciação entre o ser-aí e os outros. O tédio consiste no traço determinante do mundo atual, no qual o homem se torna desinteressante para si mesmo. Esse homem absorvido pela técnica, desarticulado da relação com sua historicidade, inviabiliza a conquista de si próprio, segundo Heidegger (2010, p. 158).
\end{abstract}

Assim, partindo dessa visão de tédio, que se dá em um contexto de mundo do qual o Dasein é co-originário, é oportuno se refletir sobre o mundo atual, ao qual chamaremos de contemporâneo. A sociedade contemporânea, denominada por Bauman (2007), de sociedade líquida, se aproxima do que Heidegger nomeia de era da técnica. Nesta, impera o imediatismo, a pressa, a eficiência e o consumo. É a mesma sociedade que tanto favorece a descoberta da cura de doenças, com os avanços na medicina, como a que fabrica muitas outras, tais como a violência, a síndrome do pânico, as depressões, o suicídio. Consequência da coisificação do ser humano, nesse contexto social, tudo se esvai, como um líquido que escorre por entre nossas mãos sem que consigamos senti-lo por muito tempo, inclusive os vínculos afetivos. É o caso do "ficar", no contexto das relações amorosas; estabeleceu-se que tal modo de relacionar-se representa a ausência de compromisso, semelhante a um "teste-drive" que se faz com um veículo, como o carro; desta feita, transferido para as relações afetivas, estas, agora, coisificadas e descartáveis.

A sociedade contemporânea é marcada pela cultura midiática, cuja filosofia preconiza a busca da beleza, a valorização da imagem, a aparência e a felicidade a todo custo. O consumo é o grande valor adotado e perseguido por todos. Consome-se de tudo: desde os fastfoods às drogas, de todas as espécies, que eliminam a dor, promovem o bem-estar e a felicidade, ainda que à custa de um 
estado de entorpecimento que "apaga" os sentimentos, e por que não dizer, elimina os sentidos de ser. Não mais é permitido ficar triste, chorar, sentir-se infeliz. Como se fosse proibido existir, no sentido da incompletude e de um ser finito, para quem o mundo será sempre inóspito. Como sentir-se infeliz num mundo repleto de soluções materiais? Portanto, com qual propósito se justifica pensar na morte e na finitude? Como ser próprio, singular, num mundo que massifica os desejos e afetos? Como atender à demanda de um mundo de ofertas atraentes, vendendo a ilusão de uma felicidade e realização pessoal como se mercadorias fossem?

Identificado com tal visão de sociedade, Baudrillard (2001), afirma:

\begin{abstract}
Hoje, a vida é preservada na medida em que tem valor, isto é, valor de troca. Mas se a vida é preciosa, é justamente porque ela não tem valor de troca- porque é impossível trocá-la por algum valor final. O mundo não pode ser negociado como mercadoria, nem trocado por qualquer outro mundo, sobretudo o mundo virtual.
\end{abstract}

Próximo a este modo de pensar encontra-se Debord (Apud Giovanetti, 2010, p. 239), ao afirmar que vivemos a sociedade do espetáculo. Já não é suficiente rompermos um relacionamento; agora, o importante é a sua publicização, de preferência, nas redes sociais. Portanto, é necessário publicar no Facebook, MSN e Orkut, se possível com fotos, a nossa dor e solidão, deixando que o nosso ethos, a nossa morada, perca os limites do seu território, confundindo-se e misturando-se com os outros, tornando-se, assim, impessoal e desenraizado da sua história. Como diz Heidegger (1981), somos "todos nós... ninguém". E a máxima dos tempos atuais parece ser esta: "apareço, logo, existo".

Assim, nesse mundo hipervirtual, técnico, eficiente e rápido, aquele que não se "adequa" ao modo-de-ser moderno e "antenado", se entedia. O jovem que alimenta o projeto de entrar na universidade, e o consegue, quase sempre após grandes e sofridas batalhas para atingir esse lugar, o que acontece, quando atinge o seu objetivo? 0 que se passa com o jovem que se atira de um prédio que abriga a sua própria sala de aula? Talvez, diante de tantas solicitações do mundo, diante de um tempo que nunca se alcança, haja vista a virtualidade das relações nesse mundo de Ipods, Ipeds, mensagens instantâneas; como então, viver essa temporalidade? Como acompanhar o ritmo da experiência de existir, diante de uma história, pessoal e de mundo, que passa e não marca, como se fosse deletada em um rápido click? Nesse contexto, então, o Dasein se depara com o tédio, encobrindo o seu poder-ser. O tempo se esvai, ou não passa. O mundo torna-se desinteressante e nada tem sentido. Passado e futuro já não apontam para um poder-ser próprio. A singularidade, esta, perdeu-se no impessoal, no "a gente". Diante de tantas 
"ilusões" perdidas, foi-se o rumo, a direção, o sentido. O ser se encobriu diante da ausência do tempo. Com isso, interroga Heidegger (1927/1999, p. 15):

\begin{abstract}
Qual o resultado negativo ou positivo das tentativas que sempre somos levados a fazer? - Não é nada mais nada menos do que a experiência originária do tempo como "pronome do ser", em retração. O ser não se deixa apreender ou determinar nem por via direta nem por desvios, nem por outra coisa nem como outra coisa. Ao contrário, exige e impõe que nos contentemos com o tempo de seu sentido e nos relacionemos com todas as realizações a partir de seu nada, isto é, a partir de seu retraimento e de sua ausência.
\end{abstract}

Assim, tal como na angústia, esse constitui o momento em que a condição de impessoalidade e de vazio existencial do Dasein se desvela na tonalidade afetiva do tédio profundo, colocando o Dasein diante da possibilidade de buscar uma existência mais própria ou permanecer no desinteresse de viver, na impessoalidade e no vazio da existência.

\title{
5 Considerações finais
}

Ao final dessas reflexões, constatamos que muito mais poderia ser dito. No entanto, ficamos na proposta das reflexões iniciais e provisórias, tal como o próprio Dasein, enquanto um ser lançado em um mundo que se apresenta inóspito e sem qualquer fixidez, já que toda verdade é relativa e provisória. Pensar o suicídio, fenômeno presente na história das civilizações, desde as mais remotas, de uma forma filosófica que rompa com um saber constituído na tradição científica, significa, sempre, uma tarefa árdua e complexa. Como reconhece Emmanuel Carneiro Leão, referindo-se à obra heideggeriana "Introdução à metafísica" (HEIDEGGER, 1999, P. 9), na sua apresentação:

Em filosofia não há possibilidade de introdução. Um abismo separa o espaço ordinário da existência, em que se move tanto o modo de ser habitual, familiar e imediato da vida cotidiana, como o modo de ser objetivo, técnico e exato da vida científica, do espaço extraordinário, em que se agita a investigação filosófica. E nenhuma ponte o poderá transpor. Não, certamente, por estar o espaço da filosofia demasiado distante e sim demasiado próximo de todos os modos de ser da existência histórica.

Tal modo de pensar a filosofia nos faz acreditar que cada passo que dermos, por menor que seja, em direção a um diferente modo de 
pensar a existência, representará uma contribuição na direção de um saber que reflita a condição humana. A condição de um Dasein que, antes de qualquer explicação ou determinação, constitui-se como um poder-ser exigindo, portanto, para o seu desvelamento, um horizonte de compreensão e respeito às singularidades humanas.

\section{Referências}

BARRIOS, L.; EVERETT, S.; SIMON, T.; BRENER, N. Suicide ideation among U.S. college students: Associations with other injury risk behaviors. Journal of the American College Health Association, v. 48, p. 229-233, 2000.

BAUMAN, Z. Tempos líquidos. Trad. Carlos Alberto Medeiros. Rio de Janeiro: Zahar, 2007.

BAUDRILLARD, J. A ilusão vital. Rio de Janeiro: Civilização Brasileira: 2001.

BORGES, V. R.; WERLANG, B. S. G. Estudo de ideação suicida em adolescentes de 15 a 19 anos. Estudos de Psicologia, Natal, v. 11, n. 3, p. 345-351, 2006. ISSN 1413-294X.

BRASIL. MINISTÉRIO DA SAÚDE. SVS - Secretaria de Vigilância em Saúde. Banco de dados dos sistemas de informação sobre a mortalidade (SIM) e nascidos vivos (SINASC)- 1998 a 2004. Brasília, 2006.

BRASIL. MINISTÉRIO DA SAÚDE. Sistema de Informações sobre Mortalidade - SIM, 2009. Disponível em: < http://tabnet.datasus.gov.br/cgi/tabcgi.exe?idb2009/c09.def>.

Acesso em: 08 out. 2011.

CALAIS, S. L.; ANDRADE, L. M. B.; LIPP, M. E. N. Diferenças de Sexo e Escolaridade na manifestação de Stress em adultos jovens. Psicologia: Reflexão e Crítica, v. 16, n. 2, p. 257-263, 2003.

CORDÁS, T. A.; SENDACZ, A. M.; GONZÁLES, D.; TOSSOLI, A. L.; BERNARDI, A.; MIZRAHI, E. I.; LEEUW, L. L. L. Ideação e tentativa de suicídio em uma população de estudantes de Medicina. Revista ABP-APAL / Associação Brasileira de Psiquiatria. Asociación Psiquiátrica de la America Latina, v. 10, n. 3, p. 100-102, 1988. DEBORD, GUY. A sociedade do espetáculo. Rio de Janeiro: Contraponto, 1997.

DUTRA, E. Ideação e tentativa de suicídio entre estudantes de psicologia da UFRN. Relatório de pesquisa apresentado à Próreitoria de Pesquisa-Propesq/UFRN, 2007.

Ideação e tentativa de suicídio entre estudantes de psicologia da UFPB. Relatório de pesquisa apresentado à Próreitoria de Pesquisa-Propesq/UFRN, 2008.

Ideação e tentativa de suicídio entre estudantes de medicina da UFRN e profissionais de saúde da rede pública de Natal. In: 
BORGES, L. O. (Org.). Os profissionais de saúde e seu trabalho São Paulo: Casa do Psicólogo, 2005, p. 281-298.

FEIJOO, A. M. C. (Org.). Tédio e finitude: da Filosofia à Psicologia. Belo Horizonte: Fundação Guimarães Rosa, 2010.

FORGUIERI, Y. C. Psicologia fenomenológica. Fundamentos, Método e Pesquisa. São Paulo: Pioneira, 1993.

GENDLIN, E. Befindlikeit: Heidegger and the Philosophy of Psychology. Journal of Existential Psychology and Psychiatry, v. 16 , n. 1-3, p. 43-71, 1978/1979.

GIOVANETTI, J. P. O tédio existencial na sociedade contemporânea. In: FEIJOO, A. M. C. (Org.). Tédio e finitude: da Filosofia à Psicologia. Belo Horizonte: Fundação Guimarães Rosa, 2010, p. 233261.

HEIDEGGER, M. Todos nós... ninguém. Um enfoque fenomenológico do social. Trad.: Dulce Critelli. São Paulo: Moraes, 1981.

. Ser e tempo. $8^{a}$ ed. Petrópolis, R.J., Vozes, 1999, V. I e II, $1927 / 1999$.

Introdução à metafísica. Trad. Emmanuel Carneiro Leão. 4a. Ed. Rio de Janeiro: Tempo Brasileiro, 1999.

- Os conceitos fundamentais da metafísica. Mundo, Finitude, Solidão. Trad. Marco Antônio Casanova. Rio de Janeiro: Forense Universitária, 2006.

KITZROW, M. The mental health needs of today's college students: Challenges and recomendations. NASPA Journal, v. 41, n. 1, p. 165-179, 2003.

MELEIRO, A. M. A. S. Suicídio entre médicos e estudantes de medicina. Revista da Associação Médica Brasileira, v. 44, n. 2, p. 135-40, 1998.

MIRANDA, P. S. C.; QUEIROZ, E. A. Pensamento suicida e tentativa de suicídio entre estudantes de Medicina. Revista ABP-APAL / Associação Brasileira de Psiquiatria. Asociación Psiquiatrica de la America Latina, v. 13, n. 4, p. 157-160, 1991.

NOVAES, R. N. A analítica fenomenológica da existência e a psicoterapia. In: FEIJOO, A. M. C. (Org.). Tédio e finitude: da Filosofia à Psicologia. Belo Horizonte: Fundação Guimarães Rosa, 2010, pp. 177-199.

SARRIERA, J. C. (Org.). Psicologia comunitária: estudos atuais. $2^{\mathrm{a}}$. Ed.Porto Alegre: Sulina, 2004.

SILVERMAN, M.; MEYER, P.; SLOANE, F.; RAFFEL, M.; PRATT, D. The Big Ten student suicide study. Suicide and Life Threatening Behavior, cidade, v. 27, p. 285-303, 1997.

SOUZA, E. R; MINAYO, M. C. S.; MALAQUIAS, J. V. Suicídio de jovens nas principais capitais do Brasil. Cadernos de Saúde Pública, Rio de Janeiro, v. 18, n. 3, p. 673-683, 2002.

SPRC- SUICIDE PREVENTION RESOURCE CENTER. Promoting Mental Health and Preventing Suicide in College and 
University Settings. U.S. Department of Health and Human Services, 2004.

WATERS, T.; DUTRA, E. Agression Direct Inward: Substance Abuse, Suicide, and Self-Harm. In: MCCARTHY, S. N.; HUTZ, C. S. (Orgs.). Preventing teen violence. A guide for parents and professionals. Westport, USA, Praeger Publishers, p. 63-77, 2006.

WECHSLER, H.; LEE, J.; KUO, M.; LEE, H. College binge drinking in the 1990s: A continuing problem: Results of the Harvard School of Public Health 199 College Alcohol Study. Journal of American College Health, v. 48, p. 199-210, 2000.

WERNECK, G. L.; HASSELMANN, M. H.; PHEBO, L. B.; VIEIRA, D. E.; GOMES, V. L. O. Suicide attempts recorded at a general hospital in Rio de Janeiro, Brazil. Cadernos de Saúde Pública, v.22, n. 10, 2006. ISSN 0102-311X.

\section{Endereço para correspondência}

\section{Elza Dutra}

Av. Prof. Olavo Montenegro, 2887 Capim Macio, Natal, RN, Brasil

Endereço eletrônico: elza_dutra@hotmail.com

Recebido em: 09/11/2011

Reformulado em: 16/10/2012

Aceito para publicação em: 20/10/2012

Acompanhamento do processo editorial: Ana Maria Lopez Calvo de Feijoo

\section{Notas}

*Docente do Programa de Pós-graduação em Psicologia PPgPsi/UFRN. 